\title{
A HIPERESCRITA DE SI: memória, experiência e invenção digital na formação de professores
}

\section{Tania Lucía Maddalena}

\section{Resumo}

O presente artigo pretende refletir sobre o conceito de hiperescrita de si, noção derivada da Tese de Doutorado da autora, que teve como objeto de estudo o relato digital, as narrativas em rede e as histórias de vida e formação na linguagem da hipermídia. A experiência da escrita digital, fazendo uso de múltiplas linguagens causadas pela convergência das mídias na Internet, foi articulada em diversas propostas didáticas da disciplina Tecnologias e Educação, entre os anos 2015 e 2018, do curso de Pedagogia da Universidade do Estado do Rio de Janeiro (UERJ). Essas experiências deixaram indícios de como operam a memória, a experiência e a invenção digital na hora de narrar sobre si. Todo o processo de escrita de si sofre fortes impactos e se potencializa quando a escrita é em rede e a experiência de formação compartilha-se no ciberespaço. Partimos do diálogo teórico-metodológico e epistemológico com as pesquisas autobiográficas em educação, as pesquisas com os cotidianos escolares e as metodologias que defendem o valor da prática sem separar pesquisa do contexto da docência, especificamente, a pesquisa-formação na cibercultura.

Palavras-chave: hiperescritas de si; blog, formação de professores; tecnologia educativa.

SELF-HYPERWRITING: memory, experience and digital invention in teacher education

\section{Abstract}

This article aims to explore the concept of self-hyperwriting, a notion derived from the author's Doctoral Thesis. The thesis aimed at studying Digital Storytelling, the network narratives and the stories of life and training in the hypermedia. The experience with digital writing on the Internet was articulated in various didactic proposals of the Technologies and Education discipline, between 2015 and 2018, in the Pedagogy course of the University of State of Rio de Janeiro (UERJ). These experiences left indications of how memory, experience and digital invention operate when it comes to narrating about itself. This whole process suffers strong impacts and is enhanced when writing is networked, and the training experience is shared in cyberspace. This work dialogues at the theoretical-methodological level and epistemologically with the Autobiographical Research in Education and the methodologies that defend the value of the practice without separating the research from the context of teaching, specifically, Research-training in Cyberculture. Keywords: self-hyperwriting; blog; teacher education; educational technology.

\section{EL HIPERRELATO AUTOBIOGRÁFICO:} memoria, experiencia e invención digital en la formación docente

\section{Resumen}

Este artículo pretende explorar el concepto de hiperrelato autobiográfico, noción derivada de la Tesis Doctoral de la autora, que tuvo como objeto de estudio el relato digital, las narrativas en red y las historias de vida y formación en el lenguaje de la hipermedia. La experiencia de escritura digital, utilizando múltiples lenguajes como fruto de la convergencia de medios en Internet, fue articulada en diversas propuestas didácticas de la disciplina Tecnologías y Educación, entre los años 2015 y 2018, en el curso de Pedagogía de la Universidad del Estado de Río de Janeiro (UERJ). Estas experiencias dejaron indicios de cómo operan la memoria, la experiencia y la invención digital a la hora de narrar sobre sí mismo. Todo este proceso sufre fuertes 
impactos y se potencia cuando la escritura es en red y la experiencia de formación se comparte en el ciberespacio. Este trabajo dialoga a nivel teórico-metodológico y epistemológicamente con las investigaciones autobiográficas en educación, las investigaciones con los cotidianos escolares y las metodologías que defienden el valor de la práctica sin separar la investigación del contexto de la docencia, específicamente, la investigación-formación en la cibercultura.

Palabras clave: hiperrelato autobiográfico; blog; formación docente; tecnología educativa.

\title{
INTRODUÇÃO
}

\author{
Escrever é o mesmo processo do ato de sonhar: \\ vão-se formando imagens, cores, atos \\ e sobretudo uma atmosfera de sonho \\ que parece uma coisa e não uma palavra. \\ Clarice Lispector
}

A escrita, uma das maiores invenções da humanidade, vem sofrendo fortes mudanças na cibercultura, nossa cultura contemporânea. A convergência de mídias conectada ao hipertexto fundou a linguagem da hipermídia (SANTAELLA, 2013), que traz inúmeras possibilidades narrativas combinando texto digital, emojis, hiperlinks, geolocalização, gifs, memes, imagens, fotografias, sons, hipervídeos, música, entre outros. É nessa linguagem que escrevemos, inventamos mundos e trocamos muitas das mensagens no nosso cotidiano. Cada dia somam-se novos fenômenos que afetam as formas de ler, escrever e entender o contexto que habitamos.

O presente artigo apresenta o conceito de hiperescrita de si na formação de professores - a experiência da escrita digital -, que foi articulada em diversas propostas didáticas da disciplina Tecnologias e Educaşão, entre os anos 2015 e 2018, no curso de Pedagogia da Universidade do Estado do Rio de Janeiro (UERJ/Maracanã). Essas experiências deixaram indícios de como operam a memória, a experiência e a ficção na hora de narrar sobre/a si. Partimos do diálogo teóricometodológico e epistemológico com as pesquisas autobiográficas em educação (JOSSO, 2004; SOUZA, 2004, 2006), as pesquisas com os cotidianos escolares (CERTEAU, 2012; ALVES, 2008, 2015) e as metodologias que defendem o valor da prática sem separar pesquisa do contexto da docência, especificamente, a pesquisa-formação na cibercultura (SANTOS, 2014).

$\mathrm{Na}$ pesquisa de doutorado realizada ${ }^{1}$, foram trabalhados quatro atos de currículo ${ }^{2}$ (MACEDO, 2013), propostas didáticas em forma de projetos: Digital Storytelling em vídeo, Visual Storytelling na rede social Instagram, o Blog como memorial hipertextual de formação e Histórias de leitores contemporâneos com o aplicativo Storybird. Neste artigo será aprofundada a experiência com os Blogs, a primeira interfase da web 2.0 que ainda resiste e pode ser utilizada com fins narrativos e formativos na educação. Concordamos com Jorge Larrosa quando destaca que: "O homem é um animal de invenção, e as diferentes formas de consciência não são senão produtos dessa função inventiva, dessa capacidade de invenção [...] produtora de novidade, de intensidade, criadora de possibilidade de vida. [...]" (LARROSA, 2002, p. 66-67).

A invenção da escrita, da imprensa, do rádio, do cinema, do computador, dos algoritmos, a maioria de tecnologias ao nosso redor precisam ser entendidos como invenções de um espaço-

\footnotetext{
${ }^{1}$ Tese de Doutorado da autora: Digital Storytelling: uma experiência de pesquisa-formação na cibercultura, orientada pela Profa Dra. Edméa Santos, disponível em http://www.proped.pro.br/teses/teses pdf/1721342013 1-1125-DO.pdf.

2 Segundo Macedo (2013, p. 17) o ato de currículo como um conceito-dispositivo cria a antítese da visão de currículo como uma condenação sociopedagógica, como um artefato que produz tão somente prescrição, restrição e trilhos. Aqui o ato de currículo é entendido como uma invenção social e cultural, com possibilidades de se transformar em uma multicriação socioeducacional, numa experiência compartilhada.
} 
tempo particular. Neste artigo não entendemos as tecnologias apenas como aparelhos e equipamentos, não é puro saber-fazer. São artefatos culturais (ALVES, 2008) que carregam implicações sociais, éticas, políticas, estéticas, económicas, educacionais. As tecnologias são também compostas pelas formas de pensar e pelos padrões de interação que emergem ao seu redor, os usos que os praticantes fazem e deixam de fazer. Todo isso entra na complexa tessitura do contexto sociotécnico que habitamos.

Trazer para o debate as hiperescritas de si é pensar nas histórias que nos constituem, é mergulhar no passado, sem perder de vista o presente e as pretensões de futuro. Todos os caminhos de formação que atravessamos falam de um lugar, possuem cheiros e sons, estão imersos num espaçotempo que lhes é próprio. É partindo dessa ideia de que a contação de histórias e a escrita de si na linguagem da hipermídia possuem uma potência marcante, pois ao narrar uma história, o narrador lança mão de inúmeras estratégias, entrelaçando experiências, memórias e ficções (MADDALENA, 2018).

\section{DA EXPERIÊNCIA VIVIDA À EXPERIÊNCIA NARRADA: HISTÓRIAS DE VIDA E FORMAÇÃO}

$\mathrm{Na}$ narração de uma história pessoal, vários elementos entram em jogo. Não se trata somente de nossas lembranças do passado, mas também de uma tessitura ligada ao contexto (atual) do nosso presente. Para quem narramos? Com que intenção? Que histórias decidimos contar e por quê? A ensaísta argentina Beatriz Sarlo, no seu livro Tempo passado: cultura da memória e guinada subjetiva (2007), apresenta um levantamento interessante concernente às relações entre memória, experiência e construção do testemunho nas narrativas pessoais. A autora sustenta que "[...] o tempo próprio da lembrança é o presente: isto é, o único tempo apropriado para lembrar e, também, o tempo do qual a lembrança se apodera, tornando-o próprio" (SARLO, 2007, p. 10). A lembrança vem para nossa memória mesmo quando não é convocada, e quando narrada não fala só do passado, mas também se refere ao presente.

A lembrança não permite ser deslocada e, de alguma maneira, precisamos dela para relatar o nosso presente. Essas visões do passado são construções, falamos do passado sem suspender o presente e, muitas vezes, fazendo referência ao futuro. Segundo Sarlo (2007, p. 48-49), “[...] o presente da enunciação é o tempo de base do discurso, porque é presente o momento de se começar a narrar e esse momento fica inscrito na narração". Isso implica que nos relatos testemunhais encontramos um narrador implicado nos/com os fatos, já que os tempos verbais do passado não ficam livres do tempo presente da enunciação.

Assim é inevitável desconsiderar o presente no ato de narrar uma história pessoal, já que as interferências do próprio tempo, o contexto e as práticas do cotidiano são marcantes no consciente e no inconsciente de cada narrador. $\mathrm{Na}$ atualidade proliferam as narrações chamadas não ficcionais (tanto no jornalismo como na etnografia social e na literatura): testemunhos, histórias de vida, entrevistas, autobiografias, lembranças e memórias, relatos identitários.

Todas elas são um claro exemplo da guinada subjetiva do nosso tempo. São narrações que recuperam o valor da palavra, que dão sentido à experiência. A dimensão intensamente subjetiva (um verdadeiro renascimento do sujeito, que nos anos 1960 e 1970 se imaginou estar morto) caracteriza o presente. Isso acontece tanto no discurso cinematográfico e plástico como no literário e no midiático. Todos os gêneros testemunhais parecem capazes de dar sentido à experiência. Um movimento de devolução da palavra, de conquista da palavra e de direito à palavra se expande, reduplicado por uma ideologia da Cura identitária 
por meio da memória social ou pessoal. O tom subjetivo marcou a pós modernidade, assim como a desconfiança ou a perda da experiência marcaram os últimos capítulos da modernidade cultural. Os direitos da primeira pessoa se apresentam, de um lado, como direitos reprimidos que devem se libertar; de outro, como instrumentos da verdade. (SARLO, 2007, p. 38-39).

O pensamento de Sarlo é interessante porque permite situar o valor da narração da experiência no contexto mais atual, fala dos diversos relatos testemunhais da contemporaneidade, especificamente após o fim das ditaduras militares na América Latina, e de como se expandiram esses testemunhos em diversos gêneros da escrita literária, cinematográfica, entre outros. Ao pensar nos gêneros da pós-modernidade que dão sentido à experiência, apresenta-se a importância da memória e do presente na tessitura da construção do relato pessoal.

A memória envolve um processo contínuo de transformação de experiências relembradas. As memórias que escolhemos recordar e relatar e a maneira pela qual damos sentido a elas são coisas que se vão modificando com o passar do tempo (THOMSON, 1997, p. 57). "Ao narrar uma história, eu a faço e sou um narradorpraticante ao traçar/trançar as redes dos múltiplos relatos que chegam até mim, neles inserindo, sempre, o fio do meu modo de contar" (ALVES, 2015, p. 147).

Tempo, memória e esquecimento. Uma trilogia para pensar a arte de lembrar, para estruturar um olhar sobre si, para revelar-se. A memória é escrita num tempo, um tempo que permite deslocamento sobre experiências. Tempo e memória que possibilitam conexões com as lembranças e esquecimentos de si, dos lugares, das pessoas, da família, da escola e das dimensões existenciais do sujeito narrador (SOUZA, 2006, p. 102-103).

É assim que construímos e reconstruímos nossos eus, constantemente, frente a cada situação com que nos deparamos. A trilogia tempo, memória e esquecimento formam parte desse processo, e a arte de lembrar (SOUZA, 2006) é fundamental na hora de escrever ou contar uma narrativa. A partilha de experiências torna-se um elemento central na pesquisa com narrativas de formação. Segundo Santos (2014) cada vez mais os saberes da experiência são valorizados e destacados na teoria contemporânea sobre a formação de professores; as experiências surgem como fontes originais dos narradores, nas quais relatam os modos singulares como vivem suas vidas através dos sentidos e significados cotidianos que dão às mesmas.

Seguindo essa linha, Marie-Cristiane Josso (2004) sustenta que a experiência formadora é uma articulação conscientemente elaborada entre atividade, sensibilidade, afetividade e ideação. Assim, para compreender a construção da experiência de formação a autora apresenta três níveis de interpretação:

a) 'ter experiências' é viver situações e acontecimentos, durante a vida, que se tornaram significativos, sem tê-los provocado;

b) 'fazer experiências' são as vivências de situações e acontecimentos que nós próprios provocamos, isto é, somos nós mesmos que criamos, de propósito, as situações para fazer experiências;

c) 'pensar sobre as experiências', tanto aquelas que tivemos sem procurá-las (modalidade a), quanto as que nós mesmos criamos (modalidade b) JOSSO, 2004, p. 51).

Para Josso (2004), a tomada de consciência sobre o processo experiencial/formativo é fundamental. Nesses três níveis de interpretação da experiência, a autora destaca a importância da narrativa. A arte de narrar experiências e vivências, que parte do pensar sobre as experiências, pode promover uma conscientização do processo formativo. A formação é um processo contínuo e 
complexo, por isso a autora sustenta que as experiências formadoras, quando narradas, contribuem para o próprio ato de formação não só do sujeito como também de seus pares.

O baseamento teórico de Josso (2004) é fundante nas pesquisas narrativas, biográficas e autobiográficas, que tem uma longa história intelectual no campo da educação. Essas pesquisas apontam que o estudo da narrativa é o estudo da maneira em que os seres humanos experimentam o mundo, vivem e constroem o cotidiano (CONNELLY, CLANDININ, 1995). Por meio de diversos dispositivos tem-se acesso às histórias de vida dos atores/atrizes da pesquisa. Podem ser documentos pessoais como: autobiografias, diários cartas, fotografias e objetos pessoais; entrevistas biográficas gravadas em áudio ou vídeo; ou dispositivos de pesquisa e formação acionados, como por exemplo a escrita dos memoriais de formação em práticas pedagógicas, entre outros. Através desses documentos escritos (em diversas linguagens) temos acesso, de alguma maneira, às experiências formativas e seus processos, dado que a experiência, quando narrada de maneira escrita, inscreve-se, fixa-se e abre caminhos para a compreensão.

La narración da conocimiento, otorga comprensión a la realidad; lo escrito explica la vida. Pero a diferencia del pensamiento, lo escrito, escrito está. Las vivencias no escritas pueden y deben olvidarse, perderse en la lejanía, en lo remoto del recuerdo que desfigura; el olvido aquí cumple su función terapéutica, libertadora, prevista por Freud. Sería imposible vivir sin una memoria capaz de olvidar; sería una condena la vida. Pero en cambio, la escritura fija y no permite el olvido. Repasar un texto antiguo significa revivir, recobrar, recordar. (FERRER, 1995, p. 166-167)

"O escrito explica a vida, o escrito, escrito está" fala Ferrer Caveró (1995, p. 166) em um texto no qual explica a força da narrativa escrita sobre as crises nos processos de formação. São inúmeras as pesquisas que trabalham na linha das histórias de vida recuperando narrativas escritas, são relatos feitos pelos sujeitos da pesquisa, nos quais a reconstrução da própria história outorga uma consciência maior da própria existência. A escrita aumenta a densidade do existir, a história se compõe assim como um diálogo entre as diversas vozes que nos habitam.

A escrita da narrativa remete ao sujeito uma dimensão de autoescuta, como se estivesse contando para si próprio suas experiências e as aprendizagens que construiu ao longo da vida, através do conhecimento de si (SOUZA, 2004, p. 13). Nesse sentido, a chamada escrita de si fundase na tessitura de práticas que provocam a autoescuta e o autoconhecimento. A escrita mobiliza reflexões profundas que exigem uma maior consciência em relação às nas narrativas orais, pois a escrita fixa, não permite o esquecimento. Nos relatos escritos há sempre uma exposição, um encontro com experiências do passado e do presente, desejos futuros, histórias de outros que afetam e entram para compor a trama. Estão ali, escritas. Mostrando um pouco de si e de todo o processo que atravessamos até chegar à dita escrita.

$\mathrm{Na}$ escrita de narrativas, a arte de evocar e de lembrar remete ao sujeito a eleger e avaliar a importância das representações sobre sua identidade, sobre as práticas formativas que viveu, de domínio exercidos por outros sobre si, de situações fortes que marcaram escolhas e questionamentos sobre suas aprendizagens, da função do outro e do contexto sobre suas escolhas, dos padrões construídos em sua história e de barreiras que precisam ser superadas para viver de forma mais intensa e comprometida consigo próprio (SOUZA, 2006b, p. 143).

Trazer essas ideias em torno da experiência e da escrita de si como um processo de autoconhecimento, para nosso entendimento do trabalho com o resgate da memória escolar, é também entender a narração de histórias como uma prática de narração de experiências que nos constitui como humanos e que nos expõe, nos toca, nos forma e transforma. 


\section{O BLOG COMO MEMORIAL HIPERTEXTUAL DE FORMAÇÃO}

Com o advento dos softwares sociais, redes sociais e interfaces sociais, se inaugura a chamada $W e b 2.0$, interfaces colaborativas livres e abertas (software de acesso livre e gratuito) surgem para propiciar a criação, atualização e disponibilização de mensagens em tempo real (online) de forma simples e interativa. Estas mudanças provocaram o surgimento de novas práticas em relação à criação de textos na internet. Textos que evoluíram mais ainda quando a utilização do hipertexto se somou à convergência das mídias.

É notório que o conceito de texto vem passando por transformações profundas desde que as tecnologias digitais entraram em uso. A integração do texto, das imagens dos mais diversos tipos, fixas e em movimento, e do som, música e ruído, em uma nova linguagem híbrida, mestiça, complexa, que é chamada de hipermídia, trouxe mudanças para o modo como entendíamos não só o texto, mas também a imagem e o som (SANTAELLA, 2007, p. 286).

Os Blogs foram a primeira interface da Web 2.0 em possibilitar a criação, edição, publicação e compartilhamento de textos por parte do usuário de maneira simples. Emergiram como uma interface virtual destinada ao registro diário de acontecimentos no ciberespaço (diário online), facilitando práticas como o diário íntimo e depois foi evoluindo para outras práticas comunicacionais como, por exemplo, o jornalismo on-line, sites pessoais, institucionais, diários de pesquisa, muitos dos quais, com a incorporação das imagens evoluíram para os fotologs (SANTOS, 2014, p. 135).

Após a evolução da interface Blog na incorporação de vídeos, fotos, músicas, links, os usuários podem contar e construir histórias hipertextuais com uma variedade de possibilidades da escrita hipertextual na linguagem da hipermídia. Embora muitos autores achem que a blogosfera sofreu uma grande queda após o surgimento das redes sociais, os portais que promovem a criação de blogs como Bloggere Wordpress não deixam de se reinventar e estão alinhados às últimas tendências.

Um dos atos de currículo que desenvolvemos na disciplina Tecnologias e Educação na UERJ foi a criação de um Blog como memorial hipertextual de formação no qual foram recopilados todos os trabalhos realizados na disciplina. Com esta proposta pretendíamos que os praticantes da pesquisa pudessem escrever sobre os aprendizados da disciplina, mas também sobre o primeiro ano na UERJ. Tentando incentivar a escrita hipertextual das narrativas autobiográficas, utilizando vídeos, links, fotografias e tudo que a plataforma escolhida tinha para a criação do blog.

Para começar foi de grande importância trabalhar a questão do hipertexto e da interatividade na internet. A escrita hipertextual é própria da hipermídia e nossa intenção foi potencializar as narrativas dos praticantes da pesquisa com elas. 
Figura 1: Aula sobre hipertexto

\section{Tania Lucía Maddalena}

16 de novembro de 2015 - Rio de Janeiro

Boa tarde turma! Hoje começamos com nosso novo projeto de criação dos Blogs pessoais de cada um de vocês, deixo aqui o vídeo que assistimos. Lembrem do que falamos, o Blog será necessário para nossa disciplina mas também pode ser utilizado depois dela como curadoria de conteúdos, como diário de suas práticas como pedagogos entre um monte de possibilidades mais, então é interessante escolher um título que seja legal e identifique vocês.

Não esqueçam de ler o texto recomendado por Edmea Santos sobre os blogs, é muito importante para entender a linguagem da hipermídia e o hipertexto que incorporaremos em nossas postagens. http://issuu.com/cenpec/docs/05_ensinar_e_aprender_blogs Recomendei duas plataformas para vocês utilizarem: Blogger e Wordpress.com, as duas são gratuitas e de fácil utilização, além do que já criaram é importante que vejam as outras possibilidades que tem na configuração, explorar os recursos sem medo, etc.

Para segunda-feira que vem 23/11 vocês tem que ter os seus blogs criados e uma primeira postagem de apresentação feita. Vamos continuar com a criação dos conteúdos em nossa aula.

Um abraço grande! Adorei nossa aula hoje! https://www.youtube.com/watch?v=X5GIHTfDNa0

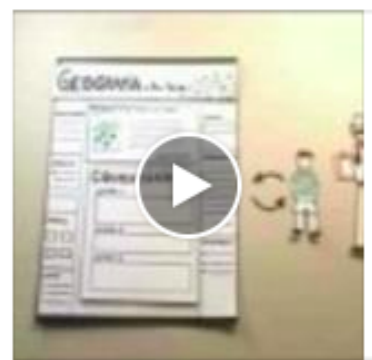

\section{O que é um blog?}

Há excelentes ferramentas Web 2.0 à disposição, gratuitas (blog, wiki, fórum, podcast, vídeo, canal de vídeo, comunidades...) basta usar. No site da rede pau...

YOUTUBE.COM

It Curtir $\quad \Rightarrow$ Comentar Compartilhar

Lu Almeida, Lena Chianello e outras 13 pessoas

$\checkmark$ Visualizado por 41

Fonte: https://www.facebook.com/groups/159822104353564/ Acesso em: 5 ago. 2019

A aula de criação dos blogs foi muito produtiva, lembro-me passando pelos computadores e ouvindo os praticantes escolherem os nomes de seus blogs, muitos rindo, outros mais reflexivos, o clima da sala de aula estava animado, no ar tinha um clima instigador. Como era uma atividade individual, cada blog ganhou o estilo do seu próprio autor, do conteúdo escrito e da maneira em que foi elaborado (no design e na estética). O blog já leva consigo a ideia de diário pessoal e, de alguma maneira, carrega esse traço íntimo sem sê-lo. 
DOI: https://doi.org/10.12957/teias.2020.48638

Figura 2: Blog de Monique Carvalho, estudante da disciplina

Monique Carvalho

29 de novembro de 2015 - Rilo de Janeiro

Boa noite, gente! Nesse primeiro ano de UERJ muita coisa mudou pra mim. Eu entendi que temos que estar atento às constantes influencias ruins que nos cercam, como aquela piada machista, aquele comentário que banaliza a violência contra a mulher, etc. Mas ainda falta MUITA desconstruçāo, e a isso, dedico meu blog.

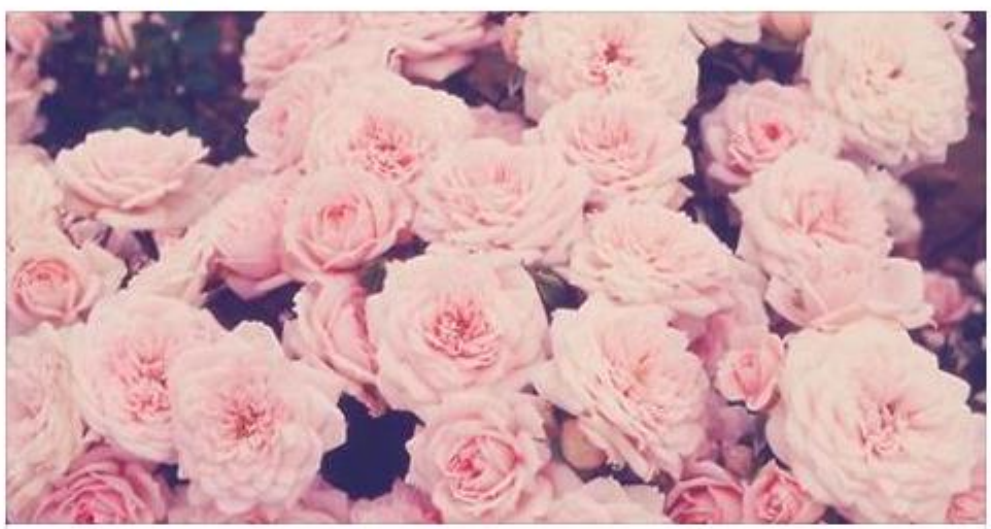

Negra, mulher, brasileira, universitária, professora, aluna.

FOFAREVOLTADA.BLOGSPOT.COM I POR MONIQUE CARVALHO

I. Curtir Comentar $\Rightarrow$ Compartilhar

Fonte: https://fofarevoltada.blogspot.com.br/33 Acesso em: 5 ago.2019

A escrita da experiência, quando invocada, possui uma capacidade formativa intrínseca. A interface Blog permitiu uma escrita hipertextual pública, na qual muitos estudantes narraram suas impressões sobre o primeiro ano na UERJ, com todas as desconstruções e aprendizados.

\section{A HIPERESCRITA DE SI: MEMÓRIA, EXPERIÊNCIA E A INVENÇÃO DIGITAL EM REDE}

O trabalho intenso com o narrar na hipermídia na disciplina Tecnologias e Educação no curso de Pedagogia/UERJ deixou rastros em narrativas, imagens e sons digitais. Nesses rastros, podemos distinguir as hiperescritas de si dos professores em formação que fizeram parte da presente pesquisa.

Trabalhar com narrativa escrita como perspectiva de formação possibilita ao sujeito aprender pela experiência, através de recordações-referências circunscritas no percurso da vida e permite entrar em contato com sentimentos, lembranças e subjetividades marcadas nas aprendizagens experienciais. $\mathrm{O}$ mergulho interior possibilita ao sujeito construir sentido para a sua narrativa, através das

\footnotetext{
${ }^{3}$ É importante dizer que os estudantes estiveram cientes da pesquisa-formação e permitiram de forma burocrática (assinando um termo de consentimento de uso de imagens e narrativas) mas também de forma sensível, criando uma relação de respeito e de troca de conhecimentos.
} 
associações livres do processo de evocação, num plano psicossomático, com base em experiências e aprendizagens construídas ao longo da vida (SOUZA, 2008, p. 93).

Ao longo da pesquisa, como foi articulado no apartado anterior, bebemos das pesquisas autobiográficas/experienciais o conceito de escrita de si e o trabalho que estas pesquisas fazem com a utilização da escrita como um dispositivo de autoconhecimento, possibilitando por meio da escrita um mergulho interior pelo qual dotamos sentido às experiências vividas. Seguindo esta linha teórica somamos ao conceito de escrita de si o prefixo hiper.

Entendemos por hiperescritas as práticas culturais de escrita na hipermídia, sempre dando prioridade a um tipo de escrita digital que possui como base a contação de histórias, sejam histórias de vida, experiências, ficções ou invenções. Para nós, as hiperescritas de si estão fundadas no hipertexto, fazem uso dele e o incorporam combinando com outros elementos digitais para narrar o cotidiano e a própria vivência experiencial pessoal de habitar e aprender no/com o mundo.

A possibilidade de combinar texto e outros tipos de signos em hiperambientes descentraliza a hierarquia linear e reconceitualiza a dimensão gráfica do texto. Por isso se fala em hiperescrito, hiperficção, hiperconto, hiperpoesia, hiperedição etc. (SANTAELLA, 2013, p. 215). Nos inspiramos nesses conceitos para falar de hiperescritas de si. Então, o que são as hiperescritas de si? São as escritas que contêm experiências, lembranças, relatos e ficções sobre si mesmo e o processo formativo, na linguagem da hipermídia. Ou seja, que utilizam e expandem a plasticidade do digital e suas possibilidades imagéticas, de hiperlinks e espaço/temporais das redes para contar histórias de vida, inventá-las e ficcionar a própria vida.

Qual é a diferença entre a escrita de si no suporte analógico e a biperescrita de si? A maior diferença é que a hiperescrita de si surge na linguagem hipermedial e absorve toda sua potência. $O$ narrador de uma história digital entende que a linguagem da Internet possibilita uma escrita expandida, pois nela integram-se e entram no jogo outros elementos estéticos e semióticos, como imagens, hashtags, localizações, GIFs, emoticons, e, sobretudo, a possibilidade de interlocução e interatividade na criação da própria narrativa.

O que traz de novo a hiperescrita de si na formação de professores? Qual é sua potência?

$\mathrm{Na}$ nossa experiência com a formação de professores na turma de Tecnologias e Educação entre 2015 e 2018, a questão da escrita hipertextual foi estudada e vivenciada em vários ângulos. O projeto do blog como memorial hipertextual de formação, caminhou nesse sentido, pois o blog se materializou como um ambiente propício para as escritas na hipermídia. Isto não significa que qualquer blog seja uma experiência de hiperescrita de si. Esta só será quando os praticantepensantes, no nosso caso professores em formação, fizerem um uso do espaço para compartilhar experiências formativas e invenções de si, narrando suas vivências e reflexões sobre as mesmas, num processo de autorização e coautoria com si mesmo.

A seguir, no diálogo com as narrativas dos praticantes da pesquisa, mostramos um dos blogs criados pelas estudantes do curso de Pedagogia, entre os anos 2015 e 2018, na disciplina Tecnologias e Educação. 
DOI: https://doi.org/10.12957/teias.2020.48638

Figura 3: Relato da estudante de Pedagogia Lena Chianello

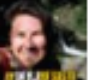

Lena Chianello

16 de novembro de 2015

Boa noite queridas professoras! Estive trabalhando na construção do novo blog durante toda a tarde de hoje, após nossa aula sobre como construir um blog. Achei a ideia muito boa, me sentindo muito motivada, pois apesar do trabalho que deu para selecionar fotos, hiperlinks, hipertextos, foi muito gratificante, pois à medida que ia construindo o blog, ia percebendo $\mathrm{a}$ importância que ele foi ganhando para mim, no sentido de demostrar um pouco de minhas vivências profissionais através da curadoria de conteúdos. Acredito que vocês nos deram um presente maravilhoso nos passando esta tarefa, pois nos proporcionaram a possibilidade de nos mostrar para o mundo, de mostrar um pouco de nosso conhecimento $e$ melhor, a possibilidade da troca de experiências. Agradeço pela possibilidade que nos deram e deixo um bj carinhoso para todas. Segue 0 link para o meu blog:

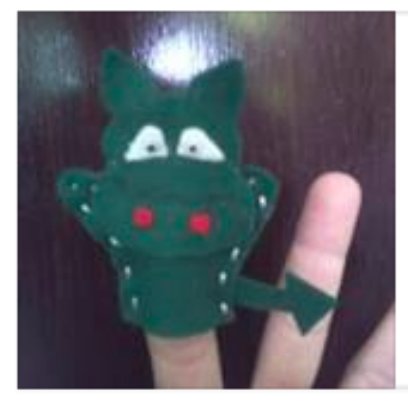

\section{O Lúdico do Brincar}

Curtir Comentar $\Rightarrow$ Compartilhar

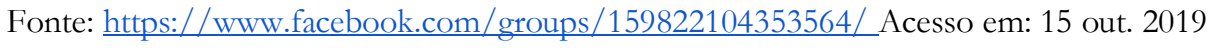

O blog O lúdico do brincar é da estudante Madalena Chianello, Lena; nele ela narra como, por meio de uma experiência formativa no Morro dos Macacos no bairro Vila Isabel (zona Norte do Rio de Janeiro), teve acesso a uma experiência lúdica com crianças que fizeram com que ela se interessasse pela educação. Lena é arquiteta e após ter contato com a educação infantil nesse espaço decidiu fazer o vestibular para Pedagogia na UERJ. No blog, ela vai apresentando os brinquedos de tecido dedoches que ela própria fez, mediante fotos e narrativas conta todo esse processo criativo e o significado que teve na vida dela a experiência como docente, uma experiência que provocou a mudança de profissão e a escolha de um novo curso na universidade. 
Figuras 4 e 5: Capturas do blog de Lena Chianello

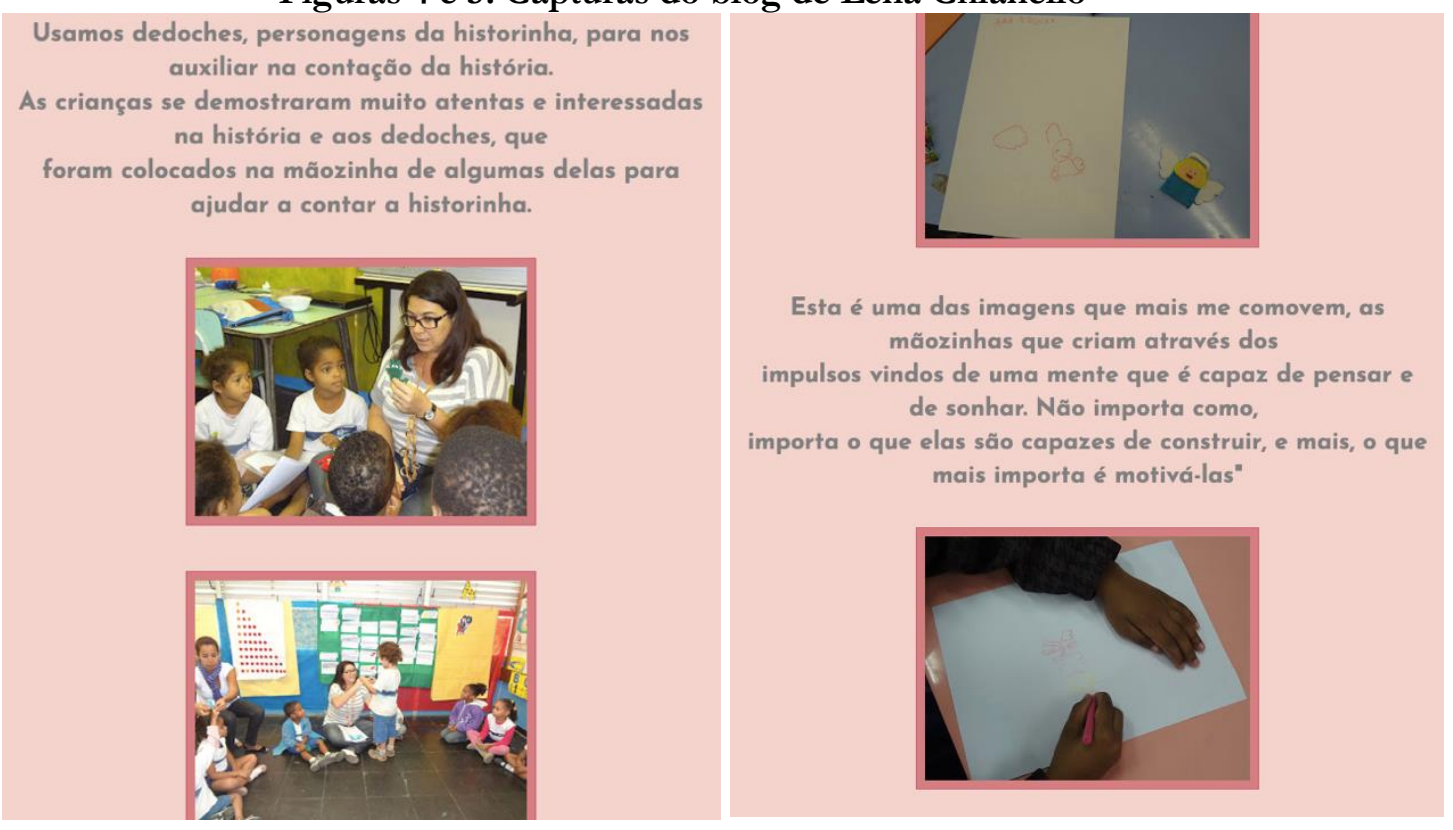

Fonte: https://oludicodobrincar.blogspot.com.br/Acesso em: 15 out. 2019

A hiperescrita da formação da Lena, como uma hiperescrita de si, revela que a escrita hipertextual da sua experiência formativa foi marcante. A busca pelas imagens, fotografias, links, o caminho que ela percorreu como professora contadora de histórias e as crianças que conheceu naquele lugar. Todo esse conjunto de imagens e narrativas que compõem o Blog nos mostram a sua história e experiência de formação e nos ajudam a entender que

São os acontecimentos vividos que formam a experiência. A experiência não é algo que sucede, é o que nos implica, portanto nos afeta, nos toca, nos mobiliza e também nos impõe, nos compromete. A experiência nunca nos deixa indiferentes. (MACEDO, 2016, p. 25)

E aqui reside uma das singularidades mais fortes das hiperescritas de si, que é a possibilidade da partilha, da narrativa em rede. O que se passa quando o acontecimento e a experiência formativa são narrados em rede?

Se entramos no mérito de que a formação se realiza como experiência irredutível enquanto autoformação, formar-se consigo mesmo, autopoieses -, enquanto heteroformação, formação com o outro, e metaformação, formação através de reflexões do sujeito sobre sua própria experiência formativa, podemos antever o quanto a formação emerge como acontecimento na medida que a imprevisibilidade habita de forma densa sua emergência. (MACEDO, 2016, p. 52)

Aprendemos com Macedo (2016) que a heteroformação, como formação com o outro, é um dos elementos que compõe e integra a visão plural do processo formativo. Assim, a maior potência do acontecimento e a experiência formativa, quando são narrados na hipermídia, é que supõem a alteridade desde sua concepção, pois quando escrevemos em ambientes digitais, a escrita pode ser pública. Seja no blog, no Facebook, na imagem do Instagram, no vídeo do Youtube, o que está 
escrito implica, sempre, um leitor, um outro que nos lê, responde, comenta, co-cria com a nossa mensagem. Isso não é menor. Nem no alcance, nem nas questões formativas que esse fato implica.

Nos últimos anos, com a liberação do polo de emissão, o desenvolvimento das redes sociais da internet, permitiu uma ampliação da enunciação das mensagens e a possibilidade que as diversas criações e autorias cheguem até espaçostempos impensáveis.

Nos etnométodos tecidos na pesquisa-formação apresentados por Macedo (2006), ele faz referência ao grupo focal na pesquisa-formação, no qual é lançada uma questão/pergunta/história e as pessoas, sentadas em círculo, começam a compartilhar sentidos, encontros e desencontros em torno ao assunto abordado. Salvando as distâncias, mas querendo fazer uma ligação crítica, o etnométodo do grupo focal possui algumas similitudes com os acontecimentos e experiências formativas compartilhadas nas redes sociais, nos quais é colocada uma questão/história/relato e começam a entrar outras vozes na construção de sentidos. Só que nas redes sociais na internet e plataformas que permitem a interatividade essas conversas possuem uma ampliação maior que a conversa de um grupo de pessoas fechados em uma sala presencial, como é no grupo focal.

O digital em rede possibilita que essa história formativa seja compartilhada ao mesmo momento em milhares de locais no planeta e que as pessoas que leem as histórias possam compartilhar, emocionar-se, se entristecer e deixar sua narrativa embaixo, entrando assim, ativamente na conversa. Pois, uma vez que essa narrativa de experiência entra na rede de maneira pública, o processo de interlocução, compartilhamento e troca começa. E, embora as escritas na hipermídia permitam a edição constante do que escrevemos, a possibilidade de apagar, mudar e autodestruir minha própria fala (como no caso do Snapchat, e Stories no Instagram, por exemplo) há também, uma potência formativa nessa efemeridade.

A experiência mais extrema, às vezes, a mais cruel, mas provavelmente, a mais enriquecedora que podemos ter da heterogeneidade, é a que nos é imposta através do encontro com o outro, enquanto limite do nosso desejo, do nosso poder e de nossa ambição. É aqui que a experiência como processo vibra, sai dos trilhos, balança na direção a diversos polos, inclina-se, retoma, incomoda-se, reflete e, na busca da compreensão valorada, se faz, fazendo-se criando o acontecimento. No encontro, a experiência se desloca, vibra, institui, realiza o acontecer. (MACEDO, 2016, p. 37)

A experiência mais extrema é aquela que acontece através do encontro com o outro, esse outro que está liberado para opinar nas redes sociais da internet, emocionar-se com a nossa narrativa, compartilhá-la ou provocar-nos. A primeira vez que percebemos a potência da experiência formativa narrada em rede foi frente ao contexto da pesquisa-formação onde vivenciamos a profunda crise da UERJ. Movimentos como \#OcupaUERJ, \#UERJresiste, \#SouUERJ, nos anos 2016 e 2017, nos fizeram ver a força dos acontecimentos narrados em rede e as histórias de vida e formação que nas redes sociais deram visibilidade ao sucateamento pelo qual nossa instituição estava atravessando. Mediante as diversas hashtags que funcionaram como hiperlinks e junção de histórias de formação, que reivindicaram pelo lugar da universidade pública desde narrativas, trazendo histórias e experiências vivenciadas na universidade, nos mostraram como a experiência como processo vibra em rede. 


\section{A HIPERESCRITA DE SI: ALGUMAS CONSIDERAÇÕES SOBRE UM CONCEITO AINDA EM CONSTRUÇÃO}

A noção da biperescrita de si surgiu com força na pesquisa de doutorado realizada pela autora. Não foi somente na experiência com os Blogs, mas em todos os outros atos de currículo nos quais foi trabalhado o narrar digital. Na pesquisa-formação na cibercultura não partimos de categorias teóricas pré-estabelecidas para comprovar fatos na prática. É a própria prática que marca o caminho, andamento da pesquisa, e vai mostrando nas suas manifestações os achados. As inspirações dos fenômenos da cibercultura são trazidos com uma intenção pedagógica. Pesquisa não é separada da intenção de docência, por isso existe uma forte implicação com a prática docente.

O conceito de invenção de si de Marie-Christine Josso (2004) nos inspira, por todas as práticas cotidianas nas quais o sujeito cria e recria o eu, desde as roupas que usa, os pratos que cozinha, até as experiências formativas pelas quais transita e deixa suas autorias. Nós partimos desde essas invenções de si no digital em rede, os processos criativos dos praticantes da nossa pesquisa aconteceram nas interfases universidade/ciberespaço. Por isso a questão do digital faz parte constitutiva dessas invenções. Nas hiperescritas de si, os praticantes autorizaram-se, narraram, criaram histórias, personagens para falar de si e dos outros, falar da própria vida e de temáticas que os instigavam.

A narrativa digital ainda tem muito caminho para ser compreendida, as hiperescritas de si é um conceito em construção, um conceito que carrega a força da memória, da experiência e da ficção entendida como invenção digital, este tripé a constitui. Muito tem se falado nas pesquisas sobre o eu na cibercultura, da possibilidade de edição constante da escrita, do direito ao esquecimento, do excesso de selfies, dos algoritmos mal-intencionados. Somos cientes de todos estes fenômenos, mas não foi a intenção trazê-los.

Na conferência TED de 2009, intitulada O perigo de uma história única, Chimamanda Ngozi Adichie após apresentar a múltiplas histórias da sua vida na África e como africana morando nos EUA, disse:

Histórias importam. Muitas histórias importam. Histórias têm sido usadas para expropriar e ressaltar o mal. Mas histórias podem também ser usadas para capacitar e humanizar. Histórias podem destruir a dignidade de um povo, mas histórias também podem reparar essa dignidade perdida.

Isto transmite um pouco o que defendo, o que me inspira e o motor que me impulsa na pesquisa com as narrativas e as hiperescritas de si na formação de professores, sei que muitas histórias importam.

\section{REFERÊNCIAS}

ALVES, Nilda. Faz bem trabalhar a memória: criação de currículos nos cotidianos, em imagens e narrativas. In: GARCIA, Alexandra.; OLIVEIRA, Inês Barbosa de (orgs.). Nilda Alves: praticantepensante de cotidianos. Belo Horizonte: Autêntica Editora, 2015, p. 207-217

ALVES, Nilda. Decifrando o Pergaminho: os cotidianos das escolas nas lógicas das redes cotidianas. In: GARCIA, Alexandra.; OLIVEIRA, Inês Barbosa de (orgs.). Nilda Alves: praticantepensante de cotidianos. Belo Horizonte: Autêntica Editora, 2015, p.133-151.

CERTEAU, Michel de. A invenção do cotidiano: 1. Artes de fazer. 20. ed. Tradução Ephraim Ferreira Alves. Petrópolis: Vozes, 2012. 
CONNELLY, Michael; CLANDININ, Jean. Relatos de experiencia e investigación narrativa. In: LARROSA, Jorge. Déjame que te cuente, ensayos sobre educación y narrativa. Barcelona: Laertes, 1995. p. 11-59.

FERRER, Virginia. La crítica como narrativa de la crisis de formación. In: LARROSA, Jorge. Déjame que te cuente, ensayos sobre educación y narrativa. Barcelona: Laertes, 1995. p. 165-190.

JOSSO, Marie-Christiane. Experiências de vida e formação. São Paulo: Cortez, 2004.

LARROSA, Jorge. Nietzssche \& a Educação. Belo Horizonte: Autêntica, 2002b.

MACEDO, Roberto Sidnei. Etnopesquisa crítica / etnopesquisa-formaşão. Brasília: Liber Livro Ed., 2006.

MACEDO, Roberto Sidnei. Atos de currículo e autonomia pedagógica. O socioconstrucionismo curricular em perspectiva. Petrópolis, Rio de Janeiro: Vozes, 2013.

MACEDO, Roberto Sidnei. A pesquisa e o acontecimento. Compreender situações, experiências e saberes acontecimentais. Salvador: EdUFBA, 2016.

MADDALENA, Tania Lucía. Digital Storytelling: uma experiência de pesquisa-formação na cibercultura. Tese de Doutorado em Educação. Universidade do Estado do Rio de Janeiro, Rio de Janeiro, 2018, $198 \mathrm{f}$.

SANTAELLA, Lúcia. Linguagens líquidas na era da mobilidade. São Paulo: Paulus, 2007.

SANTAELLA, Lúcia. Comunicação ubiqua. Repercussões na cultura e na educação. São Paulo: Paulus, 2013.

SANTAELLA, Lúcia. Gêneros discursivos híbridos na era da hipermídia. In: Bakbtiniana, São Paulo, n. 9, v. 2, ago./dez. 2014. p. 206-216.

SANTOS, Edméa. Pesquisa-formação na cibercultura. Santo Tirso, Portugal: Whitebooks, 2014.

SARLO, Beatriz. Tempo passado: cultura da memória e guinada subjetiva. São Paulo: Cia. das Letras; Belo Horizonte: UFMG, 2007.

SOUZA, Elizeu Clementino de. O conhecimento de si: narrativas do itinerário escolar e formação de professores. Tese de Doutorado. Universidade Federal da Bahia, Faculdade de Educação, 2004.

SOUZA, Elizeu Clementino de. O conbecimento de si: estágio e narrativas de formação de professores. Rio de Janeiro: DP\&A; Salvador: UNEB, 2006.

SOUZA, Elizeu Clementino de. Pesquisa narrativa e escrita (auto)biográfica: interfaces metodológicas e formativas. In: SOUZA, Elizeu Clementino de, ABRAHÃO, Maria Helena (orgs.) Tempos, narrativas e ficções: a invenção de si. Salvador: EdUNEB, 2006b.

SOUZA, Elizeu Clementino de. Histórias de Vida e Formação de Professores. In: (org.) Histórias de vida, escritas de si e abordagem experiencial. Rio de Janeiro: Quartet: FAPERJ, 2008. p. 90-95.

THOMSON, Alistair. Recompondo a memória - questões sobre a relação entre a história oral e as memórias. p. 51-84. Projeto História: Revista do Programa de Pós-graduados de história. São Paulo, v. 15, n. 2, abr. 1997. Disponível em: https://revistas.pucsp.br/index.php/revph/article/view/11216. Acesso em: 15 jun. 2017. 
DOI: https://doi.org/10.12957/teias.2020.48638

Submetido em outubro 2019.

Aprovado em janeiro 2020.

\section{Informações da autora}

Tania Lucía Maddalena

Professora no Programa de Pós-graduação em Formação de Professores para o Ensino Médio, Universidade Internacional de La Rioja, UNIR, Espanha. Doutora em Educação pelo ProPEd/UERJ.

E-mail: tlmaddalena@gmail.com

ORCID: https://orcid.org/0000-0002-3949-6491

Link Lattes: http://lattes.cnpq.br/1020426349729647 